\title{
UM ESTUDO SOBRE A IMPORTÂNCIA DO ENFERMEIRO NA ORIENTAÇÃO DA UTILIZAÇÃO DOS EQUIPAMENTOS DE PROTEÇÃO INDIVIDUAL - EPIS
}

\author{
A STUDY ON THE MALE NURSE IMPORTANCE IN THE ORIENTATION OF THE \\ USE OF THE EQUIPMENTS OF INDIVIDUAL PROTECTION - EPIS
}

\author{
Christiane Santana Costa ${ }^{1}$ \\ Cinthya Silva Valadão ${ }^{2}$ \\ Larissa Luz Alves ${ }^{3}$
}

RESUMO: Introdução: A importância do uso de equipamentos de uso de proteção individual por parte dos profissionais da enfermagem. Uma abordagem sucinta sobre o porque o uso de tais equipamentos são de fundamentais importâncias não apenas para os profissionais de enfermagem, mas para todos os que dependem de serviços de saúde. Objetivo: Descrever a importância das atribuições do profissional da enfermagem inserido em uma equipe, quanto as suas orientações acerca do uso correto dos Equipamentos de Proteção Individual pelos profissionais da saúde. Material e Métodos: Estudo da literatura envolvendo a captação de publicações científicas em língua portuguesa relacionadas ao tema aqui apresentado, destaca-se que foram utilizados para a construção do presente artigo de 22 materiais distintos, tais como: periódicos, revistas, artigos, livros, sites e outros, o8 dos materiais utilizados foram descartados e portanto, não constam no item referências bibliográficas, todos com acesso gratuitos e com datas correspondentes entre 2004 e 2020. Resultados e discussão: Foram utilizados para a construção deste artigo 30 materiais de diferentes fontes, sendo que deste total o8 foram excluídos, ressaltando, porém, que todos os materiais aqui utilizados são inerentes ao tema sobre o uso dos EPIs e o quanto o enfermeiro é importante neste processo. Considerações finais: Considera-se a respeito do tema a ajuda que um profissional da enfermagem tem para o ensino de todas as técnicas inerentes ao uso de tais equipamentos e sua importância, o que faz bem para as pessoas que dependem de um serviço de saúde.

Palavras-chave: Equipamentos. Proteção. Profissional. Enfermagem. Saúde.

ABSTRACT: Introduction: The importance of the use of equipments of use of individual protection on the part of the professionals of the enfermagem. A brief approach on the

\footnotetext{
${ }^{1}$ Lattes: http://lattes.cnpq.br/8581076669259505 Faculdade Integrada Carajás (FIC) Email:christianesantanacosta@gmail.com

${ }^{2}$ Lattes: http://lattes.cnpq.br/6395037606055193 Faculdade Integrada Carajás (FIC)

E-mail: cinthyavaladao25@gmail.com

${ }^{3}$ Lattes: http://lattes.cnpq.br/67596060197308or Faculdade Integrada Carajás (FIC)

E-mail: laryluzz@hotmail.com
} 
because the use of such equipments is not just of fundamental importances for the enfermagem professionals, but for all the ones that depend on services of health. Objective: To describe the importance of the professional's of the nursing attributions inserted in a team, as your orientations concerning the correct use of the Equipments of Individual Protection for the professionals of the health. Material and Methods: I study of the literature involving the reception of scientific publications in Portuguese language related here to the theme presented, he/she stands out that were used for the construction of the present article of 22 different materials, such as: newspapers, magazines, goods, books, sites and other, ro of the used materials were discarded and therefore, they don't consist in the item bibliographical references, all with free access and with corresponding dates between 2004 and 2020. Results and discussion: They were used for the construction of this article 30 materials of different sources, and of this total one o 8 were excluded, pointing out, however, that all the materials here used they are inherent to the theme on the use of EPIs and the as the male nurse is important in this process. Final considerations: $\mathrm{He} / \mathrm{she}$ is considered regarding the theme the help that a professional of the enfermagem has for the teaching of all the inherent techniques to the use of such equipments and your importance, what does well for the people that depend on a service of health.

Keywords: Equipments. Protection. Professionals. Nursing. Health.

\section{INTRODUÇÃO}

As dificuldades encontradas pelos profissionais de enfermagem na utilização dos

EPIs, são de certa forma tão preocupantes que, quando ao analisarmos a literatura sobre o assunto, ficamos preocupados com a segurança dos profissionais da saúde e em especial com os enfermeiros e técnicos em enfermagem, os quais serão nossos futuros colegas de profissão espalhados Brasil afora. Segundo a literatura, recebem a denominação de EPIs, todos os dispositivos de segurança que envolvem o uso individual no ambiente de trabalho, e que os mesmos estão destinados exclusivamente a proteção das pessoas que os usam, assim como para os demais que precisam dos cuidados de um profissional da saúde e principalmente do enfermeiro, haja vista que este é que esta na linha de frente no que diz respeito aos pacientes em relação aos médicos, e todos somos sabedores que o não uso destes equipamentos podem ameaçar ou colocar em risco a segurança e a saúde tanto do trabalhador quanto de outros. Partindo destas primícias, com enfoque na literatura sobre a alta incidência de acidentes de trabalho por profissionais da enfermagem e também pautado na tamanha relevância que a utilização dos EPIs tem para os profissionais citados como forma de prevenção de tais acidentes e como é importante a disseminação da conscientização para o uso de tais aparatos de segurança é que este estudo tem a sua 
construção justificada. Baseado nesse contexto, a referida pesquisa tem se a necessidade através da percepção do profissional enfermeiro e também equipe de enfermagem na consciência da importância da correta utilização dos EPIs. Quais as dificuldades encontradas pelos profissionais de enfermagem na utilização dos EPIs e qual o papel do enfermeiro frente a esta situação?

Ao analisarmos as obras literárias sobre o tema, podemos constatar como é grande a incidência de acidentes em ambientes de trabalho na área da saúde, então é com base em tais informações e na alta prevalência de acidentes de trabalho para esta classe de trabalhadores em específicos e também baseado na tamanha relevância da aplicação do uso dos materiais de proteção individual como forma de prevenção, e pautado também no benefício que a adesão destes equipamentos podem trazer é que a presente pesquisa vem abordar de forma literária como os EPIs são essenciais para uma equipe em todos os preceitos no que diz respeito a segurança. Assim, partindo de pressupostos literários e na descrição verídica que a literatura aborda sobre tal assunto, temos como objetivo principal mostrar por meio de uma pesquisa literária sobre a real importância das atribuições do profissional enfermeiro inserido em uma equipe quanto as suas orientações acerca do uso correto dos EPIs, pelos profissionais da saúde. A hipótese existente é que tais resistências, tem suas fundamentações pautadas basicamente em duas linhas distintas de visão, sendo a primeira delas pertinentes as questões da adaptação a tais equipamentos, haja vista que na maioria destes casos acontece de os equipamentos não possuir sequer os tamanhos adequados para os profissionais que irão usá-los, e então devemos reconhecer que para este caso especifico eles tem certa razão, e na segunda, talvez a mais grave, que é o simples fato de não gostarem de usar tais equipamentos e por isto, simplesmente não usam, e para estes profissionais diga-se de passagem "péssimos" profissionais, pois não estão nem um pouco preocupados com a vida de terceiros e sequer com a própria.

\section{MATERIAIS E MÉTODOS}

Por tratar-se de um estudo focado em uma revisão de literatura, e que envolve a busca e a captação de publicações científicas em língua portuguesa relacionadas ao tema aqui apresentado, faz uma abordagem sucinta sobre a importância do enfermeiro na orientação da utilização dos equipamentos de proteção individual, ou simplesmente EPIs. 
A construção do mesmo dispensa valores monetários, porém destaca-se que foram utilizados para a construção do mesmo cerca de 30 materiais distintos, sendo os mesmos compostos por: periódicos como revistas, artigos, livros, sites e outros, e vale destacar que deste total de materiais, o8 foram descartados e portanto, não constam no item referências bibliográficas.

Destaca-se que serão utilizados materiais de vários autores e pesquisadores, sobre os quais são descritos em várias de suas obras sobre os equipamentos de proteção individual, dando total ênfase para os profissionais da enfermagem, quando em seus locais de trabalhos tais como, hospitais e afins, de maneira tal que a elaboração do aqui disposto possa servir de fontes futuras para elaborações de outros trabalhos semelhantes ou na mesma linha de raciocino, afinal a segurança no trabalho deve ser tratada como algo primordial e portanto a referida pesquisa foi realizada em bancos de dados científicos eletrônicos tais como; Pubmed, Ministério do Trabalho e Emprego e Associação Nacional do Enfermeiro do Trabalho (ANENT), além de outras fontes de informação como por exemplos os sites que dão alusão ao temas pertinentes a enfermagem, e que a maioria dos materiais coletados nos bancos de dados tem suas datas de publicações correspondentes ao período de 2004 a 2020, uma vez que todos os textos que foram analisados e sintetizados auxiliaram de forma reflexiva para a construção do aqui presente, e todos materiais utilizados foram com o intuito de obter informações, porém que tais fossem de forma consistentes, no que diz respeito ao tema proposto e que as ideias de vários estudiosos sobre o tema ressalta-se que serão apresentadas e discutidas nas páginas seguintes.

Quanto a análise dos materiais selecionados, vale refletir e levantar alguns comentários pertinentes ao tema em questão, porém, no que diz respeito às limitações para a construção da referida pesquisa, esta acontece por tratar-se de um trabalho baseado em teorias e nas metodológicas, que de alguma forma dão suas contribuições e possibilitam uma compreensão quanto aos problemas que a muito tempo atingem os profissionais da saúde em especifico, e que tudo se agravou frente ao cenário pandêmico provocado pelo Corona Vírus. 


\section{RESULTADOS}

Foram analisadas cerca de 30 publicações sendo elas compostas de materiais das diversas fontes de pesquisas tais como artigos, revistas, livros e sites entre outras, destacando, porém, que deste total foram descartados um total de o8 publicações. E o fluxograma listado a seguir mostra o passo-a-passo desta evolução.

Fluxograma r: Fluxograma das etapas de inclusão e exclusão das literaturas utilizadas.

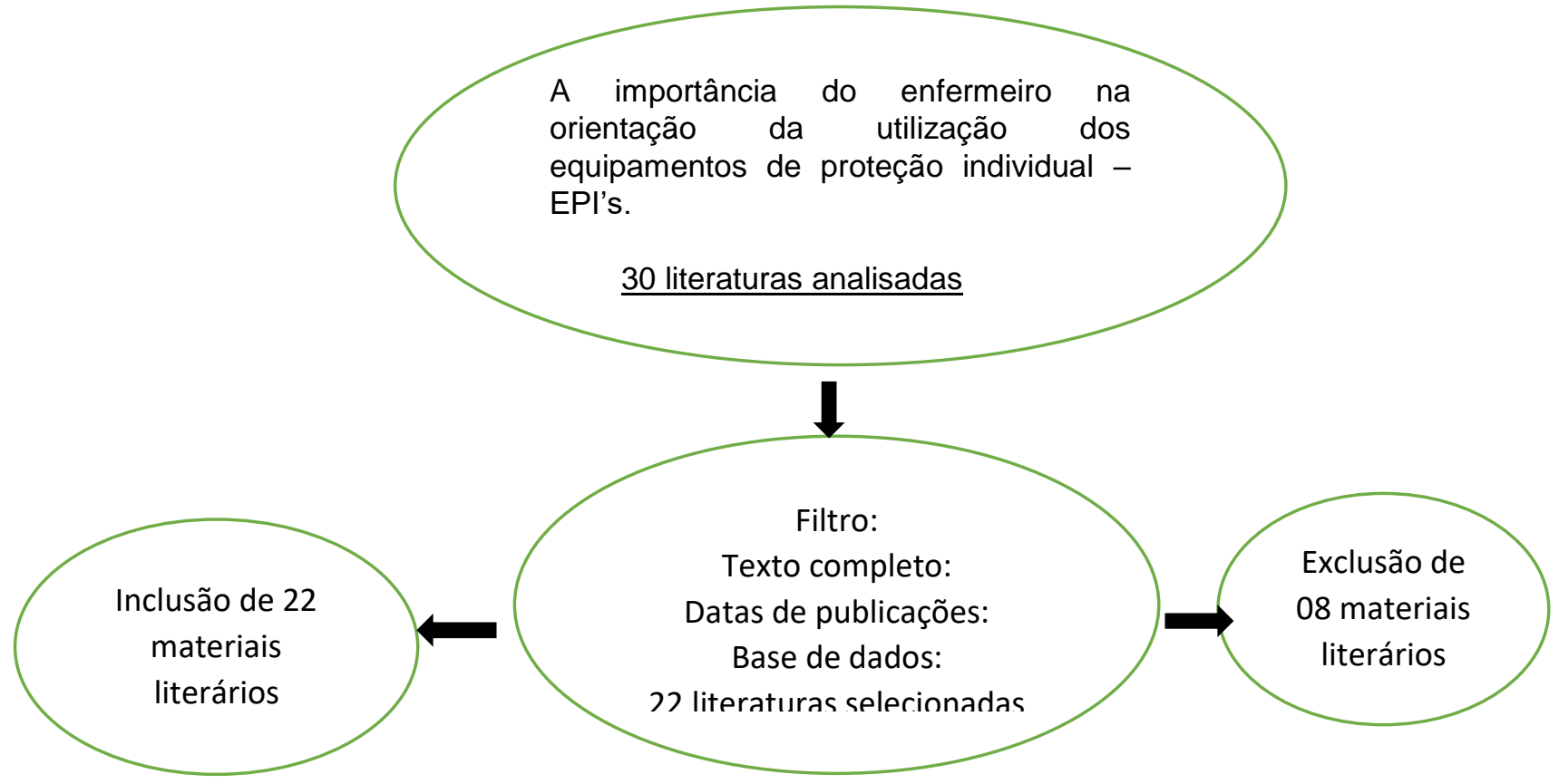

Fonte: Costa; Valadão (202I).

4. Análise literária e uma breve discussão da importância do enfermeiro na orientação da utilização dos equipamentos de proteção individual - EPI's.

Segundo Cardozo (2009), o enfermeiro tem um envolvimento histórico com o controle de infecções, sendo responsável por unidades hospitalares e por isto ele deve estar atento às várias possibilidades de transmissão de patógenos, transmissões estas que podem se dar através do profissional para o paciente ou do paciente para o profissional, e o envolvimento do profissional com o doente faz com que esta relação seja de constante risco para ambos, pois esta soma de fatores faz com que o profissional de enfermagem esteja sempre em alerta e portanto, deva sempre se preocupar com a implementação de práticas que possam oferecer condições seguras para o desempenho das atividades de toda sua equipe, além disso, incorporar à prática profissional diante dos acidentes ocorridos para garantir a seguridade de seus direitos. Então o trabalho de um profissional da Enfermagem 
está muito aquém do simples fato do exercício da função, haja vista que podemos definir este campo de atuação como a arte de cuidar e zelar pelo bem do próximo, e especificamente é este cuidado que se tem para com o ser humano é que torna tal profissão especifica, pois o desenvolvendo deste tipo de trabalho, faz com que de forma autônoma ou juntamente em equipe, as atividades que incluam a promoção, proteção, prevenção e recuperação da saúde sejam um bem e para o bem de todos os envolvidos (RUIZ; BARBOZA; ZASG, 2004).

Fiuza (2009), alerta que os acidentes de trabalho são um sério problema de saúde pública e também para a economia de um país. Em muitos setores industriais houve decréscimo de casos de acidentes do trabalho, sendo que na área da saúde ocorreu um incremento desta ocorrência, em especial no ambiente hospitalar, exigindo maiores investigações e intervenções neste contexto, tanto no sentido de prevenir como também minimizar tais ocorrências. $\mathrm{O}$ autor ainda ressalta que, nesta sistemática estão incluídos como estratégias de prevenção, o controle médico permanente, o uso de equipamentos de proteção individual, higiene nos locais de trabalho, os hábitos de higiene pessoal adequada,

o uso de vestuário adequado, vacinação e treinamentos e é esta a perspectiva corroborada por Cardozo (2009), o qual ressalta que os hospitais são locais de muita movimentação de pacientes e clientes, e que estes podem estar acometidos por diferentes problemas envolvendo a saúde de tais, o que é evidenciado em vários estudos sobre o problema, os quais têm apontado que os serviços de saúde, em particular os hospitais, de maneira geral proporcionam aos seus trabalhadores, principalmente aos da enfermagem, piores condições de trabalho em relação aos outros serviços.

\section{I Uso de equipamentos de proteção individual por profissionais da enfermagem: Um pouco de história}

Silva (2019), diz que o direito adquirido pelo trabalhador no que tange aos itens de segurança é consequência de uma formação legislativa e, portanto, algo estabelecido recentemente no Brasil, nas palavras do autor, e como sabemos por experiencias de vidas e histórias, o hábito de trabalhar em si não é algo novo, ou seja, é tão antigo quanto a existência do próprio ser humano. se voltarmos ao tempo nem tão remoto assim veremos que em todo o período da história, o ser humano sempre buscou desafios e quando voltamos ainda mais no tempo e falamos do homem primitivo, veremos que os seres 
humanos sempre foram conduzidos de forma direta, porém amargamente pela necessidade que sempre tivemos de satisfazer a fome, de garantir a defesa pessoal, enfim de garantir a nossa sobrevivência e a continuidade da nossa espécie.

Ainda no Século XII segundo Veloso (2009), surgiu as corporações de oficio diferentes das existentes na Idade média, pois estas tinham características próprias e um conceito melhorado do que eram as relações de trabalho, mesmo que estas ainda não permitiram a existência de um conjunto de leis que fossem favoráveis ao trabalhador como as que temos na atualidade, porém uma transformação estava prestes a acontecer neste setor e esta sem sombras de dúvidas era a maior já vista até então, pois garantia a liberdade do trabalhador, fato corroborado com a visão de Silva (2019), que destaca que entre os fatores internos que mais tiveram influência e corroboraram para a criação das leis que dão algum direito aos trabalhadores no Brasil está o movimento operário que contou com a participação de alguns anarquistas imigrantes e que tinha como características a organização de eventos grevistas isto ainda por volta de I8oo, prevalecendo até início de 1900, porém com o surto industrial, o efeito da Primeira Guerra Mundial tivemos uma estimada elevação do número de fábricas e consequentemente um aumento considerável no número de operários. Outro fator crucial para a ampliação das leis trabalhistas no Brasil foi a política trabalhista de Getúlio Vargas ainda em 1930, pois com a sua política que favorecia a expansão econômica e a Revolução Industrial enfim chegando ao Brasil tivemos grandes avanços nesta parte, principalmente no que diz respeito ao fato do trabalhador passar a ser assalariado.

Para Ocana (2012), é certo que desde os primeiros tempos da nossa era contemporânea o homem busca por proteção individual e isto é algo que acontece de forma espontânea, ou seja é do instinto humano, e para se ter uma ideia os primeiros Equipamentos de Proteção Individual de que já se ouviu falar datam de registros ainda da época das cavernas, época em que o homem primata dispunha de vestimentas feitas a base de peles de animais, e consta-se que tais vestes os protegiam tanto das intempéries do clima quanto de ataques de animais, e ainda na idade média, aconteceu uma grande evolução no quesito de proteção, basta lembrarmos dos filmes de cavaleiros templários que dispunham de vestimentas a base de metais como equipamento de proteção quando travavam batalhas ou até mesmo quando saiam para as caçadas, porém o primeiro relato de 
fatos com evidencias relacionados aos equipamentos de proteção individual para a segurança do trabalhador tenha ocorrido com Hipócrates (460 a 370 antes de Cristo) a quem consideram-se o "Pai da Medicina", pois ainda em sua época ele documentou uma série de doenças que os trabalhadores das minas de estanho apresentavam. Desde este primeiro relato sabemos que a evolução dos equipamentos de proteção individual não mais parou, tanto é que nos dias atuais temos um nível altíssimo de qualidade para a produção dos EPIs, aos quais sempre estamos abertos a possibilidades da criação de novos equipamentos que satisfaçam os avanços tecnológico e na are da saúde.

Em 1935, Leal (2010) descreve que o Brasil entrava de forma definitiva na era da expansão industrial, tempos de grandes alterações em todos os quadros de leis que existiam até então e fato é que todas essas alterações trouxeram mudanças significativas na vida de todas as pessoas da época e tiveram tanta importância que reflete até nos dias atuais na vida do trabalhador pois foi por meio daquelas ações que tivemos as leis em benefícios do trabalhador criadas e adequadas a cada classe, e enquanto o trabalhador passava a aprimorar suas habilidades, aumentava-se também o grau de risco relacionados as novas profissões, pois se de um lado, ele passou a se especializar em atividades que exigiam um maior conhecimento no que diz respeito às técnicas, por outro lado o profissional também passou a correr cada vez maiores riscos, e isto colocou os profissionais de diversas áreas em estado de atenção o tempo todo, uma vez que estes estavam cada vez mais expostos a acidentes com materiais cortantes, perfurantes e com altíssimo grau de contaminações.

Segundo Neto, (2012) os EPIs começaram a se destacarem como principais aliados da prevenção de acidentes e da preservação da vida do trabalhador, e ao mesmo tempo que estes evoluíram notoriamente. Tanto é que Leal, (2010) afirma que os chamados EPIs começaram a ser regulamentados no Brasil ainda entre os anos de mil novecentos e quarenta e mil novecentos e cinquenta. Quanto a evolução, tanto da criação quanto do uso dos EPIs no Brasil, devemos enfatizar que esta também aconteceu muito em função do fato de que muitas empresas do ramo multinacional, quando ao se instalarem aqui no país possibilitaram muito além do simples conhecimento do setor em que atuam, pois trouxeram além das novas tecnologias, trouxeram as metodologias que auxiliaram no ensinamento para utilização dos equipamentos. 


\subsection{Adesão e comprometimento da equipe de enfermagem na utilização dos EPIs}

A literatura da enfermagem faz um alerta que profissionais quando em campo de atuação, ou seja, quando no exercício da função de enfermeiro e ou técnico de enfermagem, a todo o momento são expostos a uma série de riscos, sendo tais riscos provenientes de microrganismos de fatores biológicos, químicos, físicos, ergonômicos, ou simplesmente aos fatores que propiciam acidentes no ambiente de trabalho, e isto gera uma grande preocupação, haja vista que temos um grande número de afecções que podem afetar os trabalhadores que lidam com as questões pertinentes a saúde humana. As questões pertinentes a acidentes de trabalho, principalmente no que tange aos ligados a saúde são de fato tão complexas que Talhaferro, Barboza e Oliveira (2008), afirmam que acidentes observados na Central de Materiais e Esterilização do Hospital de Base, localizado na cidade de São José do Rio Preto, no interior do estado de São Paulo, são quase sempre relacionados ao uso incorreto, ou o que ainda é pior ao não uso dos equipamentos de proteção individual, por parte dos profissionais de saúde que trabalham naquele local.

Vale enfatizar as palavras dos autores Carvalho e Chaves (2010), que é muito importante que a equipe de saúde tenha um tempo de aprendizagem da forma correta do uso de tais equipamentos para a proteção, afinal um pequeno tempo destinado a esta finalidade significa com certeza um grande ganho futuro, e tanto o colaborador quanto empregador deve fazer valer o direito ao zelo e bem estar de toda a equipe, daí a importância que tem quanto à escolha e ao uso correto dos EPIs, sejam em qual ambiente for, porém se resumirmos esta importância a uma Unidade de Emergência de um hospital, por exemplo ela certamente terá o seu significado aumentado de forma exponencial.

König et.al (2004) relata sobre casos ocorridos em uma unidade de emergência do extremo sul do Rio Grande do Sul, onde a autora afirma que os equipamentos de proteção individual no geral são de certa forma desconfortáveis, e que tais desconforto as vezes faz com que os profissionais que lá trabalham deixem estes equipamentos um pouco de lado não dando a devida atenção aos mesmos, e sem sombra de dúvidas quando isto acontece a aceitação por parte do usuário torna-se mais difícil e então requer a ação do profissional de saúde da área ocupacional, para fazer a solicitação que tais equipamentos sejam de imediato substituídos afim de sanar a problemática, pois os EPIs devem ser de fáceis adaptação aos trabalhadores para que o investimento desprendido em favor da aquisição de tais equipamentos, ou seja o investimento tenha sido de fato um investimento e não um mero gasto. 
Em época de Pandemia causada pelo vírus da COVID-19, temos que insistir e persistir ainda mais para a importância do uso de EPIs, haja vista que se quando havia uma certa normalidade tais equipamentos já er4am indispensáveis, imagine o atual momento que nossa população está atravessando, pois de acordo com estudos na área a inadequação dos EPIs aos funcionários causam desconforto e gera uma grande resistência ao uso dos mesmos, são por estas e outra razões que faz-se necessário o fornecimento pelo empregador de EPIs que sejam adequados e com características próprias de cada trabalhador, assim como também deve haver uma adequação a atividade desenvolvida pelo mesmo e ao risco de suas atividades, afinal os equipamentos de proteção devem proporcionar conforto e segurança, e serem portanto fornecidas com orientações e treinamentos sobre o seu uso, guarda e conservação.

\subsection{Riscos à acidentes de trabalhos que a equipe de enfermagem está exposta no ambiente hospitalar}

Os acidentes de trabalhos relacionados a profissionais da enfermagem de acordo com Balsamo e Felli (2006), podem ocorrer muitas vezes quando o profissional, as vezes por desconhecer os fatores reais de risco aos quais estão expostos muito embora os EPIs não ofereçam a segurança completa ao trabalhador, o habito do uso e correto de tais equipamentos dão uma contribuição significativa para a adoção de práticas mais seguras.

Zapparoli (2009), ressalta que a resistência ao uso de EPIs é constantemente observada em trabalhadores de saúde, e o que causa mais preocupação é que esta situação é muito mais frequente entre os profissionais de enfermagem do que se pode imaginar e que a adesão ao uso de tais equipamentos está muito abaixo do recomendado, a autora afirma ainda que em um estudo na unidade de internação do Hospital das clinicas da Faculdade de Medicina de Ribeirão Preto no Estado de São Paulo tal fato pode ser comprovado e isto levou a pesquisadora autora a uma grande preocupação, pois a utilização dos EPIs são importantes, e não falando apenas do fato de auxiliarem de alguma forma a prevenção de acidentes, com na tomada de medidas de prevenção e redução à exposição ao material biológico. Corroborando com as palavras de Zapparoli (2009) certo é que quando um trabalhador adota um comportamento seguro, isto significa que ele sabe identificar e controlar os riscos das suas atividades, e que ele usa os EPIs necessários para prevenir a 
ocorrência de acidentes e esta percepção aos verdadeiros significados que a palavra risco oferece, e o quanto este conhecimento certamente auxilia na adoção de um comportamento seguro.

Contudo, Bley, Turbay e Cunha (2004), ressaltam que a Enfermagem, dentro deste contexto ao qual está inserida, deve primar sempre pela busca de estratégias sólidas e uteis para prestar o cuidado seguro necessário para os que dela dependem, e que tais estratégias devem ser prestadas e elaboradas por um grupo de membros proativos e participantes em sua área de atuações, e que sejam diretos e responsáveis pela garantia da segurança de todos em um ambiente hospitalar, pois assim poderá garantir um melhor trato ao paciente, além de cuidar da promoção de uma cultura de segurança, levando-se em consideração algumas estratégias como a comunicação entre a equipe, a análise dos erros como oportunidade de aprendizado e a valorização do profissional através da educação continuada .

Já Carvalho e Chaves (2010) dizem que ao mesmo tempo que temos ações efetivas quanto ao uso de EPIs, podemos perceber que os bons resultados aparecerão, pois as ações bem demonstradas e desenvolvidas no ambiente hospitalar dependem, em grande parte, da capacidade do hospital em oferecer um atendimento humanizado à população, sendo necessário que seus profissionais constituam equipes capazes de promover a segurança e a qualidade nos atendimentos. Nunca se ouviu falar tanto em equipamentos de proteção individual como neste momento de Pandemia causada pelo vírus da COVID-19, talvez a presença da pandemia serviu de alerta para o quanto é importante o uso de tais equipamentos, o assunto tornou-se tão expressivo que já existe um grande debate sobre a utilização de equipamentos de proteção individual (EPI) e a utilidade que os mesmos dispensam, principalmente nos dias atuais e que se antes já eram de grande valia tudo se intensificou após o início da pandemia da COVID-ı9, e tudo isto é justificado pela necessária proteção e também pelo alto índice de transmissão do vírus.

Para ANENT (2014), os enfermeiros, assim como outros profissionais da saúde, aprendem em sua formação sobre a necessidade da utilização de EPIs, aprendendo que estes protegem suas saúdes físicas e evitam acidentes do trabalho inerentes as suas atividades. Sendo clara a necessidade da utilização, os profissionais ainda esbarram em problemas gerenciais, políticos, sociais e técnicos para o fim de utilização dos EPIs. O tema 
então tornou-se tão relevante ultimamente, devido a justiça do trabalho receber um alto número de judicialização e pedidos de indenizações e esta demanda possibilitou aqui no Brasil que o assunto fosse abordado com avides, e sabe-se que são diversos os motivos que propiciaram tal evento, porém somos por demais sabedores que tais motivos geralmente são ligados as instituições que por algum motivo não fornecem os equipamentos necessários para os seus trabalhadores, assim como temos também o mesmo problema em instituições públicas, onde a falta de tais equipamentos quase sempre são relacionadas com a administração pública e suas peculiaridades. (NISHIDE; BENATTI; ALEXANDRE, 2004).

A pandemia, em alguns termos serviu para mostrar o quão frágil é nosso sistema de saúde, tanto o público quanto o sistema privado, tivemos muitas notícias na mídia com graves relatos sobre a falta de EPIs, principalmente a falta de máscaras, luvas e respiradores artificiais e tudo isto nos mais diversos setores e estas vulnerabilidades as quais estão expostos os profissionais da saúde diante da Pandemia trouxe à mostra o grande descaso que sempre tivemos nos nossos hospitais e locais de tratamento de doentes. É dentro deste contexto que Carvalho e Chaves (2010), ressalvam que muito além dos riscos biológicos que são habituais no ambiente de trabalho, principalmente se falarmos de um Hospital, a Covid-ı́ só aumentou tal risco, pois trouxe aos profissionais de enfermagem um alto risco, que aos poucos foi tornando devastador para a sociedade, pois ao mesmo tempo que mostrou a deficiência de nosso sistema de saúde, acabou exigindo dos profissionais da saúde a exata utilização dos EPIs, tudo isto pelo simples fato da Covid-19 ser altamente contagiosa e acusar muitos óbitos, e estes relatos eram disponibilizados nos mais diversos veículos de comunicação todos os dias e infelizmente, muitos dos que faleceram no auge da Pandemia eram profissionais da saúde, sejam enfermeiros e ou técnicos de enfermagem, uma vez que estes fazem parte da linha de frente no que diz respeito a assistência direta aos acometidos pela doença.

A lei que regulamenta o uso de EPIs e que a Lei n.o 6.514/77, é uma das garantias da CLT, esta lei trata-se de um dos dispositivos de proteção e de segurança para o trabalhador, vale destacar que para melhor compreensão devemos ver os dispositivos legais que esta lei com suas junções propicia aos trabalhadores, conquanto as normas que a regulamenta não satisfazem toda as situações pertinentes, porém serve para fornecer orientações precisas 
sobre quais são os procedimentos obrigatórios cuja relação está estritamente ligada à questão segurança e a saúde do trabalhador, porém existem outros dispositivos legais para que se garanta a segurança dos profissionais, e cujos dispositivos são necessários para a compreensão do regime de trabalho para que se possa conduzir o exato direito referido. (BRASIL, 2014).

\subsection{Equipe de enfermagem e o uso dos EPIS- equipamentos de proteção individual}

No que diz respeito ao uso adequado dos EPIs, sabe-se que a supervisão do enfermeiro e as ações de educação quanto ao uso e manuseio dos mesmos deve ser permanente e direcionada para todos que estão em um ambiente propicio a contaminações, porém o destaque para o corpo de enfermagem deve ser ainda maior, pois a enfermagem é uma peça elementar neste "tabuleiro" complexo que é a prevenção de contaminantes em um ambiente hospitalar e para a adoção da prática do uso dos EPIs devemos ressaltar as palavras de Carvalho e Chaves, 2010 que afirmam que o enfermeiro quando no seu ambiente de trabalho deve executar todas as atividades relacionadas com a sua ocupação, porém no ato deste exercício ele deve se preocupar imensamente com o serviço de higiene, pois, afinal corroborando com esta linha de ideias Anent (2014) afirmam que tais medidas devem ser prioridades no que diz respeito a medicina, pois ao agir assim a equipe de enfermagem estará dando uma maior segurança e qualidade ao serviço prestado e que para tais ações sejam de fato efetivas devem ser aprimoradas por meio de estudos, visando sempre a preservação da saúde e valorização do trabalhador.

Refutando o passado, precisamente na década de 8o, (1981) quando teve início a pandemia causada pelo vírus HIV, ou simplesmente vírus da imunodefiência humana e cujo vírus tinha como característica como o próprio nome sugere a quebra na imunidade do indivíduo denomina de AIDS, e cuja enfermidade já causou desde a sua descoberta a morte de cerca de 40 milhões de pessoas em todo o mundo, e desde essa época as instituições hospitalares em quase todos os lugares do mundo passaram a se preocupar mais com a saúde dos seus trabalhadores. Como afirmam Vasconcelos, Vieira e Reis (2008), que foi neste cenário característico que surgiram várias orientações e recomendações sobre a necessidade do uso de equipamentos de proteção individual para garantir a prevenção e ao mesmo tempo que propiciaria melhorias da saúde uma vez que a segurança do profissional 
envolvido estaria garantida. Tanto é verdade tais conceitos que muitas instituições que trabalham no âmbito da saúde ou segurança do trabalho adotaram medidas para fazer valer as precauções e daí estas se tornaram padrão, pois foram adotadas como medidas de proteção aos trabalhadores, e dentre as medidas de maior equivalência para proteção individual temos o uso de EPIs e noções básicas de higiene tais como o simples ato de lavagem das mãos, desde que tais ações de higiene sejam adotadas da forma correta. (NISHIDE; BENATTI; ALEXANDRE, 2004).

De acordo com Brasil (2014) as normativas Regulamentadoras também conhecida como as NR 9, ıo, dão total ênfase para o Programa de Prevenção de Riscos Ambientais (PPRA) e apresenta muitas orientações no que diz respeito as medidas de proteção com base no controle hierárquico e que tal controle é pautado nas seguintes diretrizes.

- Medidas de proteção coletiva: De acordo Santiago (2018), tais medidas de proteção devem ser previstas e adotadas prioritariamente em todos os serviços a serem executados.

- Medidas de caráter administrativo ou de organização do trabalho: Para Lapa (2016), estas medidas são baseadas em procedimentos, em muito treinamento, e o somatório destes fatores levam a competência, facilitando a execução do trabalho.

- Uso de equipamento de proteção individual: Segundo Flores (2016), o Equipamento de Proteção Individual, ou simplesmente EPIs, devem ser adotados como sempre sendo a primeira solução, pois ao agir assim os riscos de um problema com gravidade no que diz respeito a saúde de um indivíduo se não for extinto serão em grande parte amenizados e esta é a forma correta de agir.

Nas palavras de Nishide, Benatti e Alexandre (2004), o uso adequados dos EPIs, quando aliado às medidas de proteção coletivas tornam-se essenciais, no que diz respeito a prevenção de acidentes e até mesmo ao risco de transmissão de patologias, e isto tem uma maior ênfase ainda quando relacionamos tudo isto as equipes de enfermagens, sendo que estes fazem parte de um grupo de maior exposição aos riscos ocupacionais devido ao contato direto com o paciente, uma vez que estão expostos a materiais contaminantes e perfurocortantes, então é preciso que sejam ofertadas soluções e situações que implicam em uma possibilidade bem estar destes profissionais, pois os mesmos estão quase sempre 
em contato com sangue e outros fluidos orgânicos contaminados por uma variedade de patógenos desencadeadores de doenças.

Carvalho e Cunha (2010), afirmam que no ambiente hospitalar é comumente acidentes com materiais perfurocortantes e a tudo isto somam-se os grandes riscos que normalmente já existem e dentre estes riscos podemos destacar as infecções e afecções hospitalares, sejam por meio de contaminação por vírus, bactérias e fungos, além de várias outras ocorrências que também podem causar danos à saúde do trabalhador e de outros, sem falar ainda que existe o fato de que o trabalhador no setor de saúde já sofre limitações, impostas pelas condições de vida, de saúde e também relacionadas às condições de atividade profissional.

Nishide, Benatti e Alexandre (2004), destacam ainda que dentre as ações de biossegurança que podem ser utilizadas pelos profissionais da enfermagem, podemos dar um maior destaque para as normas ligadas as precauções básicas, nas quais podemos incluir os EPIs, que tem como primícias a redução da exposição dos profissionais da enfermagem no que $\mathrm{diz}$ respeito ao contato com os agentes biológicos que causam patologias, e além de tudo isto propiciar uma recomendação correta na utilização e para o processo de descarte de material perfurocortante depois de utilizados.

Segundo Neto (2012), uma equipe de enfermagem que zele pela segurança e bem estar de todos, deve sempre fazer o uso dos EPIs, pois este bom hábito promove uma certa segurança no que diz respeito aos riscos que a atividade de um profissional da saúde está exposta, uma vez que a sua atividade o coloca frente aos perigos constantes, ou seja, em todas as situações, até mesmo em casos de emergências, uma vez que os riscos podem estar presentes no ambiente de trabalho. Muitas vezes, enquanto não seja estabelecido um diagnóstico, este é oculto, devido a este diagnóstico não deferido, o profissional muitas vezes, não possui conhecimento suficiente sobre estes riscos, fazendo com que coloque em perigo sua saúde.

No que diz respeito ao código de ética dos profissionais de enfermagem, PEBMED (2020) assegura que estes profissionais estando no exercício da função tem pleno direito quanto ao uso dos EPIs e esta garantia esta em consonância com as organizações empregadoras cujas especificidades estão previstas no Art. 63, dando total seguridade para o profissional ao exercer sua função possa desenvolver suas atividades em totais condições 
de trabalho, afinal estas garantias tem como princípios promover a própria segurança, ou seja a segurança do profissional, de seus entes e, enfim de toda coletividade que estejam direta ou indiretamente envoltos com o mesmo. E para corroborar com todo este ponto descrito acima o Art. 64 - diz que o profissional deve se recusar a desenvolver suas atividades profissionais, quando existir a falta de materiais ou equipamentos de que tem como intuito oferecer a proteção individual e coletiva dos indivíduos envolvidos no mesmo meio.

Vale então destacar que os passos iniciais para que todo o processo siga um bom caminho, é necessário decisões bem planejadas e bem executadas; uma vez que os profissionais de enfermagem principais autores do "picadeiro" da saúde estão na linha de frente e são sem sombra de dúvidas o elo de ligação entre paciente e médicos especialistas, então cabem a estes profissionais todos os cuidados no que diz respeito às prevenções quanto ao risco de acidentes, pois são estes profissionais que quando em um ambiente de trabalho passam a maior parte do tempo com os seus pacientes e familiares, e são estes profissionais também que até pelo contato direto tanto com os pacientes quanto com seus familiares são expostos a contatos com todos os tipos de afecções causadas em sua maioria por vírus, bactérias e fungos e certamente, os profissionais de saúde, por estar na linha de frente nas situações adversas, fazem parte de um grupo de risco isto em condições normais, e em tempos de Covid-ı9, estas condições são agravadas, pois estes profissionais estão em contatos diretamente aos pacientes infectados e muitas das vezes sem saber se o estão, e então soma se todas as adversidades enfrentadas por estes profissionais ao fato destes terem que administrar seus problemas.

\section{CONSIDERAÇÕES FINAIS}

O estudo foi elaborado a partir das diversas informações extraídas dos diversos materiais de estudos pertinentes ao tema proposto, e na elaboração do presente artigo percebeu-se, que, baseado nas diversas literaturas, são vários os fatores que influenciam de forma negativa o não uso ou uso incorreto dos EPIs- Equipamento de Proteção Individual pelos profissionais da saúde, principalmente da enfermagem, e constatou-se também baseado nas literaturas analisadas que a adesão ao uso dos EPIs, como equipamento de segurança pelos profissionais da enfermagem, quando ocorre da forma adequada é capaz de 
produzir bem-estar e segurança aos profissionais da saúde, e o enfermeiro por estabelecer uma relação direta tanto com familiares de pacientes quanto com as equipes médicas são os principais disseminadores de informações e orientações, haja vista que estes são os autores principais e portanto, responsáveis direta e indiretamente para que isto aconteça.

As obras analisadas mostraram também, que são várias as estratégias utilizadas pelos profissionais da enfermagem que usam os EPIs e defendem o uso de tais equipamentos para o melhoramento do ambiente de trabalho e assim como também para a efetiva adesão ao uso destes equipamentos por parte de todos envoltos em um ambiente hospitalar por exemplo, bem como a percepção do enfermeiro junto com sua equipe de enfermagem para a plena adesão e sensibilização através de capacitações, reuniões e educação permanente, afinal esta visão e modo de agir também fortalece tanto as equipes da saúde envoltas neste processo como também a da segurança do paciente. Ressaltando ainda que toda esta colaboração dos profissionais da saúde que praticam este bom ato estão agindo dentro da ética e da legislação, e ética e direito é um dever e compromisso de todos.

\section{REFERÊNCIAS}

ASSOCIAÇÃO NACIONAL DE ENFERMAGEM DO TRABALHO - ANENT. Perfil e Atribuições do Enfermeiro do Trabalho, 2014. Disponível em: 〈http://www.anent.org.br/perfil-e-atribuicoes. .. Acesso em: 27/o8/202I.

BALSAMO, A. C.; FELLI, V. E. A. Estudo sobre os acidentes de trabalho com exposição aos líquidos Corporais humanos em trabalhadores da saúde de um hospital universitário. Revista Latino-am Enfermagem, v.I4, n.3, p.346-353, 2006.

BLEY, J. Z.; TURBAY, J. C. F.; CUNHA, O. J. Comportamento seguro - ciência e senso comum na gestão dos aspectos humanos em saúde e segurança no trabalho. 2004. Disponível em: 〈http://www.comportamento.com.br/artigos_detail.asp?id_artigos=5 $>$. Acesso em: Acesso em: 27/o8/2021.

BRASIL. Ministério do Trabalho e Emprego. Norma Regulamentador n.9, de 8 de junho de 1978: Programa de Prevenção de Riscos Ambientais -PPRA.In: Normas Regulamentadoras. Brasília,2014.

CARDOZO D.A.A. A importância do uso de EPI's na prática de enfermagem, em Juiz de Fora/MG [Monografia]. Juiz de Fora: Pós-graduação em Enfermagem do Trabalho/FIJ; 2009 . 
CARVALHO, J. F. de S.; CHAVES, L. D. P.. Supervisão de enfermagem no uso de equipamento de proteção individual em um hospital geral. Cogitar e Enfermagem, Ribeirão Preto, v. 15, n. 3, p. 513-520, 2010.

FLORES, C. Hierarquia das Medidas de Controle e a "Cultura do EPI". 2016. Disponível em: $\langle$ https://www.sabersst.com.br >hierarquia_medidas_controles/...>. Acesso em: 31/o8/2021.

FIUZA C. C. Avaliação do nível de conhecimento dos trabalhadores de enfermagem do Hospital Municipal de Paracatu - MG acerca dos riscos ocupacionais, em Paracatu/MG [Monografia]. Paracatu: Faculdade de Enfermagem/FATEC; 2009.

KÖNIG, A. B. et al. Acidentes de trabalho: um olhar para uma unidade de emergência. In: Congresso brasileiro de enfermagem; enfermagem hoje: Coragem de experimentar muitos modos de ser,56, 2004, gramado. anais. gramado: Aben-seção-RS, 2004.

LAPA, R. P. As medidas de controle: Mitigando os riscos. 20r6. Disponível em:< https://segurancatemfuturo.com.br > 2016/o7/28 > as-medidas-de-controles-mitigando-osriscos/..>. Acesso em: 31/o8/2021.

LEAL, T. V. Risco Zero e treinamentos para o uso dos EPIs. Disponível em:< Https:/ riscozerotreinamentos.blogspot.com.br/2010/o7/evolucao-dos-epi.html>. Acesso em oI/o9/202I.

NETO, N. W. A história da profissão técnico de segurança do trabalho. 2012. Disponível em: 〈https:// segurancadotrabalhonwn.com/a-historia-da-profissao-tecnico-de-segurancadotrabalho/>. Acesso em 02/o9/202I

NISHIDE, V. M.; BENATTI, M. C. C; ALEXANDRE, N. C. Ocorrência de acidente do trabalho em uma unidade de terapia intensiva. Rev. Latino-Am. Enfermagem, Ribeirão Preto, v.12, n.2, p.204-21I, 2004.

OCANA, V. Historia dos Equipamentos de Proteção Individual EPIs. Disponível em: 〈https:// dicas-epis cas-epi.blogspot.com.br/2012/o6/historia-do-epi-equipamento-deprotecao.html>Acesso em oI/o9/2021.

PENMED. O direito ao uso de EPI por profissionais de enfermagem. 2020. Disponível em: 〈https://pebmed.com.br > o-direito-ao-uso-de-epi-por-pr...2020〉. Acesso em: 3I/o8/202I.

RUIZ, M.; Barboza, D. B; ZASG, S. Acidentes de trabalho: um estudo sobre está ocorrência em um hospital geral. Arq Ciênc Saúde. 2004; 4-II: 219-24.

SANTIAGO, A. NR-ı: Segurança em Instalações e Serviços em Eletricidade. 2018. Disponível em:<https://radioprotecaonapratica.com.br/nr-Io-seguranca-em-instalacoes-eservicos-em eletricidade 
/\#: :text=Conforme\%2oestabelece\%20a\%20NR\%2C\%20as,Obst\%C3\%Aiculos.> . Acesso em: 02/09/2021.

SILVA. R. P da. A formação e a evolução histórica do direito do trabalho no Brasil e no Mundo. 2019. Disponível em: <https:// conteudojuridico.com.br/consulta/Artigos/53078/a-formacao-e-a-evolucao-historica-dodireito-do-trabalho-no-brasil-e-no-mundo>. Acesso em ol/o9/2021.

TAlHAFERRO, B; BARBOZA, D. B; OliveirA, A. R. de. Adesão ao uso dos equipamentos de proteção individual pela enfermagem. Rev. Ciênc. Méd., Campinas, v. I7, n.3-6, p157-166, 2008.

VASCONCELOS, B. M; REIS, A. L. R. M; VIEIRA, M. S. Uso de equipamentos de proteção individual pela equipe de enfermagem de um hospital do município de Coronel Fabriciano. Rev. Enfermagem Integrada, Ipatinga: Unileste-MG, v.I,n.I, p.99-III, 2008.

VELOSO. C. S. Evolução histórica do direito do trabalho. 2009. Disponível em: 〈https www.tudo sobreconcursos.com/materiais/direito-dotrabalho/evolucao-historica-dodireito-do-trabalho-no-brasil-e-no-mundo>. Acesso em: 02/09/2021

ZAPPAROLI, A. Dos S. A Promoção da saúde do trabalhador em enfermagem: análise da prática segura do uso de luvas na punção venosa periférica. 2009. Tese (Doutorado em Enfermagem) -Escola de Enfermagem, Universidade de São Paulo, Ribeirão Preto; 2009. 